\section{Commentary: Postcardiotomy shock: Are stones still unturned?}

\author{
Eric Etchill, MD, MPH, and Glenn J. R. Whitman, MD
}

In this issue of the Journal, Mariscalco and colleagues ${ }^{1}$ evaluate patients undergoing extracorporeal membrane oxygenation for postcardiotomy shock using an international registry involving 19 cardiac surgical centers between 2010 and 2018. Specifically, in those 781 patients, they evaluated peripheral versus central cannulation, with a primary outcome of mortality and secondary outcomes including massive bleeding, reoperations for bleeding, and transfusions of more than 9 packed red blood cell units, among others. The authors performed a systematic review and meta-analysis of 15 retrospective studies (2491 patients) that also specifically examined the 2 cannulation techniques, looking at similar outcomes.

After significant statistical manipulation to allow for meaningful comparisons, the registry data revealed a $10 \%$ mortality benefit to peripheral cannulation $(61 \%$ vs $71 \%$ mortality, $P<.02)$. Furthermore, after appropriate adjustments, bleeding, reoperations for bleeding, and massive transfusions, all occurred more frequently in the centrally cannulated group. Not surprisingly, central cannulation was associated with fewer vascular complications as seen in the registry (odds ratio, 0.8 ) or the meta-analysis (relative risk, 0.62), but, surprisingly, less sepsis (odds ratio, $0.64 ; P=.05$ ).

We applaud the authors' careful statistical analyses and attempts to examine causal effect by controlling for the many inherent confounding variables present in an observational study of this sort. However, despite the baseline covariates that were controlled, matched, and adjusted, readers must be cautious, because the validity of the results of this study rests on the assumption that there is no remaining systematic difference between the 2 populations evaluated. ${ }^{2}$ It would be difficult to ignore the likelihood that there are unmeasured, unaccounted, and

\footnotetext{
From the Division of Cardiac Surgery, Department of Surgery, Johns Hopkins School of Medicine, Baltimore, Md.

Disclosures: Authors have nothing to disclose with regard to commercial support.

Received for publication Oct 28, 2019; revisions received Oct 28, 2019; accepted for publication Oct 29, 2019; available ahead of print Dec 6, 2019.

Address for reprints: Glenn J. R. Whitman, MD, Johns Hopkins Hospital, Zayed Tower, Suite 7107, 1800 Orleans St, Baltimore, MD 21287 (E-mail: gwhitman@ jhmi.edu).

J Thorac Cardiovasc Surg 2020;160:1217-8

$0022-5223 / \$ 36.00$

Copyright (c) 2019 by The American Association for Thoracic Surgery

https://doi.org/10.1016/j.jtcvs.2019.10.180
}

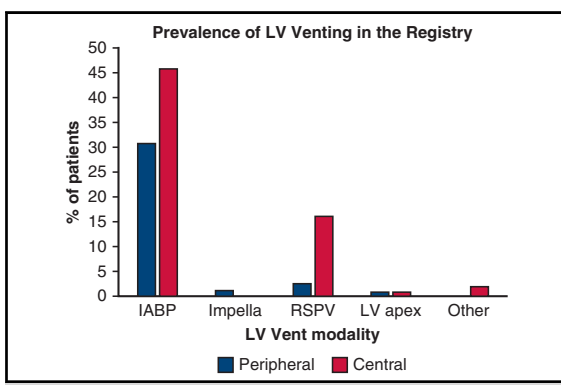

Prevalence of approaches for LV unloading during extracorporeal membrane oxygenation for postcardiotomy shock.

\section{CENTRAL MESSAGE \\ Peripheral as opposed to central extracorporeal membrane oxygenation for postcardiotomy shock appears to improve sur- vival with fewer complications, but the overall mortality rate of $60 \%$ still represents a significant opportunity.}

significant treatment selection biases that affected clinicians' behavior during implementation of postcardiotomy extracorporeal membrane oxygenation in these 2 analyses. That note of caution having been said, the similarities in outcomes between the registry data and the meta-analysis are reassuring, because important differences between the 2 treatment groups, including mortality, bleeding, reoperations, and vascular complication rates, were similar.

Whether or not you are swayed by the study's conclusion, inescapable is the fact that the outcome represents a disappointing failure to rescue rate of approximately $65 \%$. It is true that this is a select group of the sickest of the sick, culled from the entirety of patients operated upon in 19 centers over 8 years. Yet, the issue remains, can we do better? Although many specifics regarding the treatment of these patients are not known, at the risk of sounding like a "Johnny One-Note," left ventricle (LV) decompression appears woefully underused. ${ }^{3}$ True, $30 \%$ to $50 \%$ of patients received an intra-aortic balloon pump, perhaps beneficial, but the weakest of modalities at our disposal. ${ }^{4-6}$ Less than $1 \%$ received an Impella (Abiomed, Danvers, Mass) (Table E4), a more effective modality, and less than $1 \%$ received right superior pulmonary vein or direct LV apical venting (transseptal was not even mentioned), arguably the most effective approach. ${ }^{6-9}$ 
Although the clinical justification for $\mathrm{LV}$ venting is mounting, its physiologic basis is undeniable, that is, $\mathrm{LV}$ wall tension, a major determinant of myocardial oxygen consumption is directly related to recovery of function after an ischemic insult.

As we continue to struggle with those patients who are unable to wean off pump or who fail in the immediate postoperative period, we must apply all reasonable, evidence-based approaches to their care, leaving no stone unturned. The data from Mariscalco and colleagues ${ }^{1}$ suggest at least one stone still remains relatively undisturbed.

\section{References}

1. Mariscalco G, Salsano A, Fiore A, Dalén M, Ruggieri VG, Saeed D, et al. Peripheral versus central extracorporeal membrane oxygenation for postcardiotomy shock: multicenter registry, systematic review, and meta-analysis. J Thorac Cardiovasc Surg. 2020;160:1207-16.e44.

2. Austin PC, Stuart EA. Moving towards best practice when using inverse probability of treatment weighting (IPTW) using the propensity score to es- timate causal treatment effects in observational studies. Stat Med. 2015;34: 3661-79.

3. Whitman GJR. Extracorporeal membrane oxygenation for the treatment of postcardiotomy shock. J Thorac Cardiovasc Surg. 2017;153:95-101.

4. Petroni T, Harrois A, Amour J, Lebreton G, Brechot N, Tanaka S, et al. Intra-aortic balloon pump effects on macrocirculation and microcirculation in cardiogenic shock patients supported by venoarterial extracorporeal membrane oxygenation. Crit Care Med. 2014;42:2075-82.

5. Chen K, Hou J, Tang H, Hu S. Concurrent implantation of intra-aortic balloon pump and extracorporeal membrane oxygenation improved survival of patients with postcardiotomy cardiogenic shock. Artif Organs. 2019;43:142-9.

6. Russo JJ, Aleksova N, Pitcher I, Couture E, Parlow S, Faraz M, et al. Left ventricular unloading during extracorporeal membrane oxygenation in patients with cardiogenic shock. J Am Coll Cardiol. 2019;73:654-62.

7. Pappalardo F, Schulte C, Pieri M, Schrage B, Contri R, Soeffker G, et al. Concomitant implantation of Impella ${ }^{\circ}$ on top of veno-arterial extracorporeal membrane oxygenation may improve survival of patients with cardiogenic shock. Eur J Heart Fail. 2017;19:404-12.

8. Cheng A, Swartz MF, Massey HT. Impella to unload the left ventricle during peripheral extracorporeal membrane oxygenation. ASAIO J. 2013;59:533-6.

9. Lorusso R. Are two crutches better than one? The ongoing dilemma on the effects and need for left ventricular unloading during veno-arterial extracorporeal membrane oxygenation. Eur J Heart Fail. 2017;19:413-5.

\section{Commentary: Greater loss with central extracorporeal membrane oxygenation}

\begin{abstract}
Wan Kee Kim, MD, ${ }^{\mathrm{a}}$ and Joon Bum Kim, MD, $\mathrm{PhD}^{\mathrm{b}}$
Swift establishment of mechanical hemodynamic support is undoubtedly the strongest salvage procedure for patients with postcardiotomy cardiogenic shock (PCS) refractory to maximal medical management. ${ }^{1}$ Nevertheless, reported mortality rates after venoarterial extracorporeal membrane oxygenation (VA-ECMO) therapy, the most widely used mechanical support for PCS reported in the literature, have been discouraging, ranging from $50 \%$ to $75 \%$. ${ }^{2,3}$ Regretfully, arguments for the best approach for VAECMO remain inconclusive, particularly regarding whether
\end{abstract}

From the ${ }^{\mathrm{a} D e p a r t m e n t}$ of Thoracic and Cardiovascular Surgery, Sejong General Hospital, Bucheon, Gyeonggi-do and ${ }^{\mathrm{b}}$ Department of Thoracic and Cardiovascular Surgery, Asan Medical Center, University of Ulsan College of Medicine, Seoul, South Korea.

Disclosures: Authors have nothing to disclose with regard to commercial support.

Received for publication Nov 15, 2019; revisions received Nov 15, 2019; accepted for publication Nov 15, 2019; available ahead of print Dec 7, 2019.

Address for correspondence: Joon Bum Kim, MD, PhD, Department of Thoracic and Cardiovascular Surgery, Asan Medical Center, University of Ulsan College of Medicine, 88, Olympic-ro 43-gil, Songpa-gu, Seoul 05505, Republic of Korea (E-mail: jbkim1975@amc.seoul.kr).

J Thorac Cardiovasc Surg 2020;160:1218-9

$0022-5223 / \$ 36.00$

Copyright (c) 2019 by The American Association for Thoracic Surgery

https://doi.org/10.1016/j.jtcvs.2019.11.063

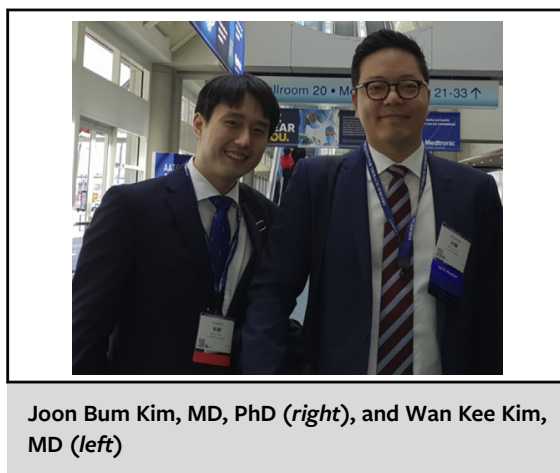

CENTRAL MESSAGE

The question of central or peripheral venoarterial extracorpo-

real membrane oxygenation

(VA-ECMO) for postcardiotomy

shock requires an individualized

approach. However, peripheral

VA-ECMO may be associated

with more favorable outcomes

when feasible. 